\title{
Diagnostic yield of esophagogastroduodenoscopy in children with chronic abdominal pain
}

\author{
Ulas Emre Akbulut ${ }^{1}$, Hamdi Cihan Emeksiz² ${ }^{2}$ Fatma Gulgun Kocak ${ }^{3}$, Ayten Livaoglu ${ }^{3}$
}

\begin{abstract}
1Department of Pediatric Gastroenterology, Hepatology and Nutrition, Kanuni Training and Research Hospital, Trabzon, Turkey

2Department of Pediatric Endocrinology and Diabetes, Kanuni Training and Research Hospital, Trabzon, Turkey

${ }^{3}$ Department of Pathology, Kanuni Training and Research Hospital, Trabzon, Turkey
\end{abstract}

Submitted: 27 December 2016

Accepted: 16 April 2017

Arch Med Sci 2018; 14, 1: 74-80

DOI: https://doi.org/10.5114/aoms.2017.67675

Copyright $\odot 2017$ termedia \& Banach

\begin{abstract}
Introduction: Chronic abdominal pain (CAP) is one of the most common indications of esophagogastroduodenoscopy (EGD) in the pediatric population. However, there is not enough information about the diagnostic yield of EGD in children with CAP. We aimed to evaluate the diagnostic yield of EGD in children with CAP in the Eastern Black Sea region of Turkey.

Material and methods: The study included children $(n=372)$ who underwent EGD for the primary indication of chronic abdominal pain during an 18-month period. We collected data on demographic features (age, sex), clinical characteristics (alarm symptoms), and EGD results for each patient. Results: Patients' mean age was 13 years (range: $4-17$ years; mean \pm SD: $12.65 \pm 3.39$ years), and the majority were female $(n=234,62.9 \%)$. Endoscopy was diagnostic in 209 patients (56.2\%; $95 \% \mathrm{Cl}$ : 30.35-40.05\%). The most common diagnosis was Helicobacter pylori gastritis (35.2\%) followed by reflux esophagitis. Significantly greater diagnostic yield of EGD was determined in patients with alarm symptoms (65.1\%) compared to those without $(45.2 \%)(\mathrm{OR}=2.26,95 \% \mathrm{Cl}: 1.49-3.44, p=0.001)$.

Conclusions: We determined a high diagnostic yield of EGD in children with CAP. Although the diagnostic yield of EGD in the assessment of CAP was found to be higher in the presence of alarm symptoms, a significant number of children without alarm symptoms were also found to have gastrointestinal system pathology diagnosed by EGD.
\end{abstract}

Key words: children, abdominal pain, endoscopy.

\section{Introduction}

Chronic abdominal pain (CAP) is one of the most common indications of esophagogastroduodenoscopy (EGD) in the pediatric population. The CAP has a negative impact on the daily life of children and causes anxiety in parents. It is demonstrated by three or more bouts in at least a threemonth period [1]. This symptom can also be an indicator of severe diseases that needs to be clarified [2]. Since most of the pediatric CAP was functional, EGD was not recommended in children with this type of pain $[3,4]$. Particularly, in pediatric cases with normal abdominal examination and without alarm symptoms, the diagnosis of functional abdominal pain is likely without the need for further investigation $[4,5]$. Moreover,

\author{
Corresponding author: \\ Ulas Emre Akbulut MD \\ Department of Pediatric \\ Gastroenterology, \\ Hepatology \\ and Nutrition \\ Kanuni Training \\ and Research Hospital \\ 61100 Trabzon, Turkey \\ Phone: +90 05053572207 \\ E-mail: ulasemre@hotmail. \\ com
}


previous studies have shown that EGD has a low diagnostic yield in children with CAP (4\%) [6]. However, the small sample size and disregard of specific histopathological findings such as reflux esophagitis or eosinophilic esophagitis as pathological in most of these studies might have undermined their power and reliability. In contrast to earlier research, wider-ranging studies conducted in recent years have shown that EGD has a rather high diagnostic yield of 35-38\% in children with CAP [7-9].

In this study, we aimed to evaluate the diagnostic yield of EGD in children with CAP of unknown etiology in the Eastern Black Sea region of Turkey.

\section{Material and methods}

This prospective study was performed at the Kanuni Training and Research Hospital Pediatric Gastroenterology Department with 398 children with CAP who were 4-17 years old and undergoing EGD over a 16-month period. The hospital is a tertiary health centre in the Eastern Black Sea region of Turkey, which has a population of approximately 2.7 million (the population of those aged $4-17$ is approximately 800,000 ). Following approval by the local ethics committee and with the explicit consent of patients and/or parents, the study was performed in accordance with the Declaration of Helsinki.

Subjects with previous known organic diseases (such as inflammatory bowel disease, celiac disease, or peptic ulcer), with a history of corticosteroid or nonsteroidal anti-inflammatory drug use, with psychiatric disorders and/or neurological diseases (such as cerebral palsy), or who had previously undergone gastrointestinal endoscopy were excluded from the study.

All patients enrolled were evaluated individually (UEA). Age, sex, height for age, duration of $a b$ dominal pain, presence of alarm symptoms, previous proton-pump inhibitor (PPI) use, presence of Helicobacter pylori and/or peptic ulcers in the family (in parents or siblings), and laboratory data (hemoglobin, platelet number, sedimentation, amylase, albumin and antitissue transglutaminase IgA (tTG-IgA)) were recorded for all subjects. Dysphagia, weight loss, chronic diarrhea (for more than 2 weeks), abdominal pain awaking the child from sleep (at least $25 \%$ of pain attacks awaking the child), persistent right upper quadrant pain, unexplained fever, persistent vomiting, retardation of growth (height $<-2$ SD for age), family history of inflammatory bowel disease (in parents or siblings), gastrointestinal bleeding (history, physical examination, or occult blood in stool), anemia (hemoglobin $<11 \mathrm{mg} / \mathrm{dl}$ ), and elevation of erythrocyte sedimentation rate (ESR) (ESR > 20/h) were regarded as alarm symptoms $[4,10,11]$.
Esophagogastroduodenoscopy was performed in all patients with alarm symptoms. However, it was also performed in children with CAP severe enough to significantly affect routine daily activities, who did not respond to the treatment administered (PPI), who had constipation that improved with treatment but without any remission in persistent pain in the epigastric region, and/or whose parents experienced serious anxiety even in the absence of alarm symptoms (social indication). However, patients undergoing EGD for the evaluation of elevated tTG-IgA ( $>200 \mathrm{RU} / \mathrm{ml}$ ) were not included.

Esophagogastroduodenoscopy procedures were performed by a pediatric endoscopist (UEA) in the endoscopy unit using an Olympus GIF-H180 device. Gross endoscopic findings such as peptic ulcer and erosion in the distal esophagus and stomach were regarded as pathological. Nonspecific findings such as hyperemia or increased or decreased vascularity were not considered pathological [12, 13].

At least two biopsies, from the esophagus, stomach (antrum) and the second part of the duodenum, were taken for all patients. Biopsy specimens were evaluated by two pathologists blinded to patients' clinical status and endoscopic findings (FGK, AL). Findings such as papillary elongation in the esophagus, basal cell hyperplasia, and an increase in intraepithelial neutrophils were evaluated in favor of reflux esophagitis [14]. These patients received PPI therapy (lansoprazole $1 \mathrm{mg} / \mathrm{kg}$ per dose twice daily) for 8 weeks, and their dietary habits were modified. Their symptoms resolved at the end of treatment; reflux esophagitis was regarded as the cause of CAP, and EGD was considered diagnostic. The presence of nonspecific histopathological changes such as reactive changes, edema, and mild inflammation was not regarded as pathological. Eosinophilia in the esophagus was defined as $\geq 30$ eosinophils in one high-power field and/or observation of eosinophilic microabscesses [15]. In these cases, EGD was repeated subsequent to the administration of high-dose PPI (lansoprazole $1 \mathrm{mg} / \mathrm{kg}$ per dose twice daily) for 8 weeks. Persisting eosinophilia in the esophagus was regarded as eosinophilic esophagitis (EoE) [15]. Histopathological findings for gastric mucosa were assessed using the Sidney scoring system [16]. Inflammation was classified as mild, moderate, or severe depending on the density of lymphocyte and plasma cells in the lamina propria. Mild inflammation was not regarded as pathological. These patients received PPI therapy (lansoprazole $1 \mathrm{mg} / \mathrm{kg}$ per dose twice daily) for 8 weeks, and their dietary habits were modified. Their symptoms resolved at the end of treatment; gastritis was regarded as the cause of 
CAP, and EGD was considered diagnostic. The presence of $H$. pylori infection was defined as the presence of $H$. pylori at antral biopsy and of positive rapid urease test $[12,13,17]$. When symptoms of the patient resolved and $H$. pylori stool antigen test became negative after the treatment of clarithromycin $15 \mathrm{mg} / \mathrm{kg} /$ day for 2 weeks, amoxicillin $50 \mathrm{mg} / \mathrm{kg} /$ day for 2 weeks and lansoprazole $1 \mathrm{mg} /$ $\mathrm{kg}$ per dose twice daily for 4 weeks, then CAP was linked to $H$. pylori infection, and EGD was considered diagnostic. The detection of $\geq 30$ eosinophils in the stomach and $\geq 25$ eosinophils in the duodenum in at least five high-power fields subsequent to the exclusion of parasitic infections, $H$. pylori infection, celiac disease, inflammatory bowel disease, hypereosinophilic syndrome, malignity, and connective tissue diseases (Churg-Strauss syn-

Table I. Demographic characteristics of patients

\begin{tabular}{|c|c|}
\hline Parameter & Value \\
\hline Total patients, $n$ & 372 \\
\hline \multicolumn{2}{|l|}{ Gender, $n(\%)$ : } \\
\hline Female & $234(62.9)$ \\
\hline Male & $138(37.1)$ \\
\hline Age, mean \pm SD (range) [years] & $\begin{array}{c}12.65 \pm 3.39 \\
(4-17)\end{array}$ \\
\hline $\begin{array}{l}\text { Duration of abdominal pain, mean } \pm \\
\text { SD (range) [months] }\end{array}$ & $\begin{array}{l}15.11 \pm 16.20 \\
\quad(3-120)\end{array}$ \\
\hline Patients using PPI, $n(\%)$ & $32(8.6)$ \\
\hline Patients with constipation, $n(\%)$ & $57(15.3)$ \\
\hline $\begin{array}{l}\text { History of H. pylori infection and/or } \\
\text { ulcer disease in family, } n(\%)\end{array}$ & $123(33.0)$ \\
\hline \multicolumn{2}{|l|}{ Patients with alarm symptoms, $n(\%)$ : } \\
\hline Elevated ESR & $19(5.1)$ \\
\hline Anemia & $25(6.7)$ \\
\hline Dysphagia & $58(15.5)$ \\
\hline Persistent vomiting & $21(5.6)$ \\
\hline Weight loss & $32(8.6)$ \\
\hline Awakens from sleep & $113(30.3)$ \\
\hline Growth failure & $30(8.0)$ \\
\hline Chronic diarrhea & $6(1.6)$ \\
\hline Rectal bleeding & $9(2.4)$ \\
\hline Unexplained fever & $2(0.5)$ \\
\hline \multicolumn{2}{|c|}{ Endoscopic-histopathological findings, $n$ (\%): } \\
\hline H. pylori gastritis & $131(35.2)$ \\
\hline Erosive gastritis & $11(2.9)$ \\
\hline Gastric ulcer & $7(1.9)$ \\
\hline Duodenal ulcer & $23(6.1)$ \\
\hline Reflux esophagitis & $32(8.6)$ \\
\hline Eosinophilic esophagitis & $2(0.5)$ \\
\hline Eosinophilic gastroenteritis & $2(0.5)$ \\
\hline Crohn's disease & $1(0.3)$ \\
\hline
\end{tabular}

drome etc.) was regarded as eosinophilic gastroenteritis (EG) [18].

\section{Statistical analysis}

Data were analyzed on SPSS 13.0 software (SPSS Inc., Chicago, IL). Descriptive statistics were presented as mean \pm standard deviation (SD). Student's $t$ test was used for normally distributed variables in two-group comparisons and the Mann-Whitney $U$ test for non-normally distributed variables. The $\chi^{2}$ test was used to compare categorical variables. Odds ratios (ORs) and 95\% confidence intervals (Cls) were calculated between groups. Significance was set at $p<0.05$.

\section{Results}

Esophagogastroduodenoscopy was performed on 398 children with CAP. Twenty-two patients from whom sufficient biopsy material could not be taken or with missing data were excluded from the study. Four patients exhibited tTG-IgA positivity (> $200 \mathrm{RU} / \mathrm{ml}$ ). A total of 372 patients were thus finally enrolled. Patients' mean age was 13 years (range: $4-17$ years; mean \pm SD: $12.65 \pm 3.39$ years), and the majority were female ( $n=234,62.9 \%)$. Mean duration of abdominal pain was 18 months (range: $3-120$ months; mean \pm SD: $15.11 \pm 16.20$ months). Thirty-two (8.6\%) patients had a history of PPI use for at least 1 week before presenting to our clinic. Mean length of PPI use was 4 weeks. Constipation was present in 57 (15.3\%) patients. A history of $H$. pylori and/or peptic ulcers was present in the families of 123 (33.0\%) patients (Table I). Thrombocytosis $\left(>4 \times 10^{5} \mathrm{~K} / \mu \mathrm{l}\right)$ was detected in 32 (8.6\%), whereas no amylase elevation (> $120 \mathrm{U} / \mathrm{l}$ ) or hypoalbuminemia $(<3.5 \mathrm{~g} / \mathrm{dl})$ was detected in any patient. Alarm symptoms were present in 204 (54.8\%) patients, of whom 90 (24.1\%) exhibited two or more alarm symptoms. Alarm symptoms of patients are detailed in Table I.

Resolution of symptoms and negativity in the H. pylori stool antigen test occurred in 131 (87.3\%) of the 150 patients in whom $\mathrm{H}$. pylori gastritis was determined. Abdominal pain symptoms resolved after treatment in 11 (78.5\%) of the 14 patients with erosive gastritis and 32 (82.0\%) of the 39 patients with reflux esophagitis, and EGD was considered diagnostic in these patients. Symptoms resolved after treatment in all patients with peptic ulcer, and absence of ulcer was determined at control EGD. Eosinophilia was detected in the esophagus of 2 patients. These patients were treated with PPI for 8 weeks and then reevaluated by control EGD. Eosinophilia was found to be persisting in both patients after 8 weeks of PPI treatment. Thus these 2 patients received the diagnosis of eosinophilic esophagitis. Two other 
patients were diagnosed with eosinophilic gastroenteritis. Symptoms of patients with eosinophilic esophagitis and gastroenteritis resolved after an elimination diet.

Endoscopy was diagnostic in 209 patients (56.2\%; 95\% Cl: 30.35-40.05\%). The most common diagnosis was $H$. pylori gastritis (35.2\%) followed by reflux esophagitis. Abdominal pain, weight loss, and elevated ESR persisting over the previous 6 months were present in a 16-year-old girl diagnosed with Crohn's disease (Table I).

No correlation was determined between patients' age and sex and the diagnostic yield of the EGD procedure. In terms of the diagnostic yield of EGD, no difference was determined between subjects using or not using PPI, with or without constipation, with or without $H$. pylori infection and/ or peptic ulcers in the family, or with or without thrombocytosis (Table II).

No significant difference in diagnostic yield of EGD was found when patients with alarm symptoms including elevated ESR, persistent vomiting, rectal bleeding, dysphagia and growth retardation were compared with patients without these symptoms. However, the diagnostic yield of EGD was greater in children with weight loss $(p=0.004$, $\mathrm{OR}=3.71,95 \% \mathrm{Cl}: 1.49-9.26)$, anemia ( $p=0.018$, $\mathrm{OR}=3.34,95 \% \mathrm{Cl}: 1.22-9.11$ ) or abdominal pain awaking the child from sleep compared to those without $(p<0.001, \mathrm{OR}=2.74,95 \% \mathrm{Cl}: 1.70-4.44)$ (Table II).

No difference was observed between patients with or without alarm symptoms in terms of sex, age, duration of abdominal pain, PPI use or presence of $H$. pylori and/or peptic ulcer in the family $(p>0.05)$, whereas a higher rate of constipation constipation was determined in patients with alarm symptoms $(p=0.032)$. The diagnostic yield of EGD was $65.1 \%$ in patients with alarm symptoms and $45.2 \%$ in patients without alarm symptoms. Significantly greater diagnostic yield of EGD was determined in patients with alarm symptoms compared to those without $(p=0.001, \mathrm{OR}=2.26$, 95\% Cl: 1.49-3.44) (Table III).

\section{Discussion}

In contrast to earlier research, recent studies have shown that EGD has a high diagnostic yield in children with CAP. Thakkar et al. determined a diagnostic yield for EGD in children with CAP of $38 \%$ [9]. Sheiko et al. determined endoscopic abnormality in $28.9 \%$ of children with CAP undergoing endoscopy and histopathological abnormality in $35.2 \%$ [8]. The diagnostic yield of EGD in children with CAP in our study was high with a rate of $56.2 \%$. Helicobacter pylori (+) gastritis (35.2\%) was the most common diagnosis, followed by reflux esophagitis (8.6\%).
Table II. Comparison of EGD with diagnostic yield with EGD without diagnostic yield

\begin{tabular}{|c|c|c|c|}
\hline Parameter & $\begin{array}{c}\text { Diagnostic, } \\
n(\%)\end{array}$ & $\begin{array}{l}\text { Nondiagnos- } \\
\text { tic, } n(\%)\end{array}$ & $P$-value \\
\hline \multicolumn{4}{|l|}{ Gender: } \\
\hline Male & $74(35.4)$ & $64(39.2)$ & 0.329 \\
\hline Female & $135(64.6)$ & $99(60.8)$ & \\
\hline Age [years] & $12.87 \pm 3.39$ & $12.25 \pm 3.37$ & 0.741 \\
\hline \multicolumn{4}{|c|}{ Thrombocytosis: } \\
\hline Present & $19(9.1)$ & $13(7.9)$ & 0.463 \\
\hline Absent & $190(90.9)$ & $150(92.1)$ & \\
\hline \multicolumn{4}{|c|}{ Constipation: } \\
\hline Present & $32(14.8)$ & $25(15.3)$ & 0.909 \\
\hline Absent & 177 (85.2) & $138(84.7)$ & \\
\hline
\end{tabular}

\begin{tabular}{lccc|}
\hline PPI use: & & & \\
\hline Present & $17(8.1)$ & $15(9.2)$ & 0.586 \\
\hline Absent & $192(91.9)$ & $148(90.8)$ &
\end{tabular}

\begin{tabular}{llll}
\hline Alarm symptom: & & & \\
\hline Present & $133(63.6)$ & $71(43.5)$ & 0.015 \\
\hline Absent & $76(34.4)$ & $92(56.5)$ &
\end{tabular}

\begin{tabular}{lccc}
$\geq 2$ Alarm symptoms: & & \\
\hline Present & $67(32.0)$ & $23(14.1)$ & 0.017 \\
\hline Absent & $142(68.0)$ & $140(85.9)$ &
\end{tabular}

\begin{tabular}{lccc}
\hline Elevated ESR: & & & \\
\hline Present & $11(5.2)$ & $8(4.9)$ & 0.950 \\
\hline Absent & $198(94.8)$ & $155(95.1)$ &
\end{tabular}

\begin{tabular}{|lccc|}
\hline Anemia: & & & \\
\hline Present & $20(9.5)$ & $5(3.0)$ & 0.018 \\
\hline Absent & $189(91.5)$ & $158(97.0)$ & \\
\hline Dysphagia: & & & \\
\hline Present & $38(18.1)$ & $20(12.2)$ & 0.121 \\
\hline Absent & $171(81.9)$ & $143(87.8)$ & \\
\hline
\end{tabular}

Persistent vomiting:

\begin{tabular}{|cccc|}
\hline Present & $12(5.7)$ & $9(5.5)$ & 0.882 \\
\hline Absent & $197(94.3)$ & $154(94.5)$ & \\
\hline Weight loss: & & & \\
\hline Present & $26(12.4)$ & $6(3.6)$ & 0.004 \\
\hline Absent & $183(87.6)$ & $157(96.4)$ & \\
\hline
\end{tabular}

Awaking from sleep:

\begin{tabular}{lccl}
\hline Present & $82(39.2)$ & $31(19.0)$ & $<0.001$ \\
\hline Absent & $127(60.8)$ & $132(81.0)$
\end{tabular}

Growth failure:

\begin{tabular}{lccc|}
\hline Present & $20(9.5)$ & $10(6.1)$ & 0.231 \\
\hline Absent & $189(91.5)$ & $153(93.9)$ & \\
\hline
\end{tabular}

ESR - erythrocyte sedimentation rate, $P P I$ - proton pump inhibitor. 
Table III. Comparison of patient characteristics, diagnostic yield and endoscopic abnormalities with respect to the presence of alarm symptoms

\begin{tabular}{|c|c|c|c|}
\hline Parameter & $\begin{array}{l}\text { Alarm symptoms }(+) \\
\qquad(n=204)\end{array}$ & $\begin{array}{l}\text { Alarm symptoms }(-) \\
\qquad(n=168)\end{array}$ & $P$-value \\
\hline Female, $n(\%)$ & $133(65.1)$ & $101(60.1)$ & 0.268 \\
\hline Age, mean \pm SD (range) [years] & $12.70 \pm 3.40$ & $12.60 \pm 3.38$ & 0.748 \\
\hline $\begin{array}{l}\text { Duration of abdominal pain, mean } \pm \text { SD (range) } \\
\text { [months] }\end{array}$ & $13.94 \pm 16.25$ & $16.01 \pm 15.60$ & 0.368 \\
\hline Patients using PPI, $n(\%)$ & $21(10.3)$ & $11(6.5)$ & 0.200 \\
\hline Patients with constipation, $n(\%)$ & $39(19.1)$ & $18(10.7)$ & 0.032 \\
\hline $\begin{array}{l}\text { History of } H . \text { pylori infection and/or ulcer disease } \\
\text { in family, } n(\%)\end{array}$ & $71(34.8)$ & $52(31)$ & 0.513 \\
\hline Diagnostic yield, $n(\%)$ & $133(65.1)$ & $76(45.2)$ & 0.001 \\
\hline
\end{tabular}

PPI - proton pump inhibitor.

Some studies have reported that children manifesting CAP with alarm symptoms often have the functional type of CAP $[10,19]$. Gijsbers et al. found that alarm symptoms were present in $59 \%$ of children with functional CAP [10]. Moreover, they indicated that alarm symptoms were useful in the diagnosis of significant diseases such as Crohn's disease but useless in the diagnostic process of functional CAP. In another study, Thakkar et al. diagnosed gastrointestinal system (GIS) pathologies by EGD with a high rate (39\%) in children having CAP with alarm symptoms. However, in contrast to Gijsbers et al., they diagnosed GIS pathologies by EGD in a considerable proportion (34\%) of children with CAP and without alarm symptoms [9]. Furthermore, they reported diagnostic yields for EGD in the presence of two or more alarm symptoms but not with one [9]. In our study, we found that EGD has a high diagnostic yield in children having CAP with alarm symptom(s) compared to those without. Of note, we also detected GIS pathologies in $45.2 \%$ of children with CAP even in the absence of alarm symptoms.

Thakkar et al. diagnosed $H$. pylori gastritis by EGD in 8 (2.8\%) of 290 children with CAP. However, in our study, $H$. pylori (+) gastritis was the most common pathology in children with CAP (35.2\%). The prevalence of $H$. pylori infection in Europe is $6.5-31.0 \%$ [20-22], whereas it is reported at $53.0-66.3 \%$ in Turkey [23-26]. The most important risk factors for the spread of $H$. pylori infection are a low socioeconomic level, poor living and hygiene conditions, crowded conditions and intra-familial contact. The infection spreads from person to person through fecal-oral or oral-oral transmission [27]. The relation between $H$. pylori infection and CAP in children is still the subject of debate. Apart from peptic ulcer development, no proven association has been found between CAP and $H$. pylori infection [28-31]. In addition, some studies have reported that there is no improve- ment in abdominal pain or gastric inflammation following $H$. pylori eradication in children [32]. In contrast, the eradication of $H$. pylori infection has been recommended by certain reports in children with CAP living in endemic areas [27, 33, 34]. In Turkey, Ozen et al. identified $H$. pylori infection in $60.3 \%$ of children presenting with CAP [35]. Moreover, they observed resolution of CAP in a significant majority of children (87\%) with the eradication of $H$. pylori infection. These findings suggest that $H$. pylori infection may be an important cause of CAP in children living in areas where this infection is endemic.

The second most common pathological finding in our study was reflux esophagitis (8.6\%). The diagnosis of esophagitis has increased in recent years due to the increase in the prevalence of gastroesophageal reflux as well as to the improvements in diagnostic methods. Thakkar et al. reported that the rate of reflux esophagitis was $21 \%$ in their series of 290 children with CAP [9]. In that study, the symptom of CAP was resolved in $62 \%$ of the children with reflux esophagitis after anti-reflux treatment (PPI or $\mathrm{H} 2$ blockers). The European Society for Paediatric Gastroenterology Hepatology and Nutrition (ESPGHAN) and the European Society of Gastrointestinal Endoscopy (ESGE) do not recommend EGD in cases of uncomplicated gastroesophageal reflux, whereas they suggest performing EGD in cases of chronic GERD to exclude other diseases or for surveillance of Barrett esophagus in pediatric patients [36]. In our study and, in similar previous studies, the frequency of reflux esophagitis was found to be considerably high in children presenting with CAP. Therefore endoscopy may be performed to exclude reflux esophagitis in selected pediatric patients with CAP.

Esophagogastroduodenoscopy is generally considered to be safe for all ages [37]. In a pediatric cohort study with a series of 345 endoscopic procedures (231 EGD alone, 26 colonoscopy alone, 
44 combined EGD and colonoscopy), adverse events were reported in only $20(5.8 \%)$ of the interventions (14 procedure-related, 6 anesthesia/ sedation related) and none of the adverse events reported were fatal [38]. Despite the given low rate of adverse events during endoscopy, to minimize the complication rate, EGD should only be performed with appropriate indications. In the recent guidelines by the ESPGHAN and ESGE, EGD was recommended in the presence of alarm symptoms such as weight loss, persistent vomiting, retardation of growth, unexplained anemia, chronic diarrhea, dysphagia or gastrointestinal bleeding in pediatric patients [36].

In our study, even though findings such as histopathological reactive changes, edema and mild inflammation were not regarded as pathological, we determined a high diagnostic yield of EGD in children with CAP. Although the diagnostic yield of EGD in the assessment of CAP was found to be higher in the presence of alarm symptoms, a significant number of children without alarm symptoms were also found to have GIS disorders diagnosed by EGD. Additionally, in contrast to the studies from Europe and the US, the rate of $H$. pylori infection was found to be high among children with CAP in our study. However, our study was limited to children referred to the gastroenterology centre due to CAP. Our sample therefore represents only a small percentage of all children with CAP. Additionally, the need for biopsy to determine CAP-related GIS diseases including reflux esophagitis and $H$. pylori infection is controversial.

In conclusion, we suggest that EGD can be performed even in the absence of alarm symptoms in children having persisting CAP despite comprehensive clinical evaluation, laboratory investigation and appropriate empiric drug use. Because EGD is an invasive procedure, further wider-ranging studies are needed to establish when and under what conditions EGD should be used in children with CAP.

\section{Conflict of interest}

The authors declare no conflict of interest.

\section{References}

1. Apley J. Recurrent abdominal pain. Br J Clin Pract 1959; 13: 586-7.

2. Dhroove G, Chogle A, Saps M. A million-dollar work-up for abdominal pain: is it worth it? J Pediatr Gastroenterol Nutr 2010; 51: 579-83.

3. Di Lorenzo C, Colletti RB, Lehmann HP, et al. Chronic abdominal pain in children: a technical report of the American Academy of Pediatrics and the North American Society for Pediatric Gastroenterology, Hepatology and Nutrition. J Pediatr Gastroenterol Nutr 2005; 40: 245-61.
4. Rasquin A, Di Lorenzo C, Forbes D, et al. Childhood functional gastrointestinal disorders: child/adolescent. Gastroenterology 2006; 130: 1527-37.

5. Yacob D, Di Lorenzo C. Functional abdominal pain: all roads lead to Rome (criteria). Pediatr Ann 2009; 38: 253-8.

6. Thakkar K, Gilger MA, Shulman RJ, El Serag HB. EGD in children with abdominal pain: a systematic review. Am J Gastroenterol 2007; 102: 654-61.

7. Thakkar K, Chen L, Tatevian N, et al. Diagnostic yield of oesophagogastroduodenoscopy in children with abdominal pain. Aliment Pharmacol Ther 2009; 30: 662-9.

8. Sheiko MA, Feinstein JA, Capocelli KE, Kramer RE. Diagnostic yield of EGD in children: a retrospective single-center study of 1000 cases. Gastrointest Endosc 2013; 78: 47-54.

9. Thakkar K, Chen L, Tessier ME, Gilger MA. Outcomes of children after esophagogastroduodenoscopy for chronic abdominal pain. Clin Gastroenterol Hepatol 2014; 12: 963-9.

10. Gijsbers CF, Benninga MA, Schweizer JJ, Kneepkens CM, Vergouwe Y, Büller HA. Validation of the Rome III criteria and alarm symptoms for recurrent abdominal pain in children. J Pediatr Gastroenterol Nutr 2014; 58: 779-85.

11. Tam YH, Chan KW, To KF, et al. Impact of pediatric Rome III criteria of functional dyspepsia on the diagnostic yield of upper endoscopy and predictors for a positive endoscopic finding. J Pediatr Gastroenterol Nutr 2011; 52: 387-91.

12. Hassall E. Macroscopic versus microscopic diagnosis of reflux esophagitis: erosions or eosinophils? J Pediatr Gastroenterol Nutr 1996; 22: 321-5.

13. Rudolph CD, Mazur LJ, Liptak GS, et al. Guidelines for evaluation and treatment of gastroesophageal reflux in infants and children: recommendations of the North American Society for Pediatric Gastroenterology and Nutrition. J Pediatr Gastroenterol Nutr 2001; 32 (suppl 2): S1-S31.

14. Krugmann J, Neumann H, Vieth M, Armstrong D. What is the role of endoscopy and oesophageal biopsies in the management of GERD? Best Pract Res Clin Gastroenterol 2013; 27: 373-85.

15. Papadopoulou A, Koletzko S, Heuschkel R, et al. Management guidelines of eosinophilic esophagitis in childhood. J Pediatr Gastroenterol Nutr 2014; 58: 107-18.

16. Dixon MF, Genta RM, Yardley JH, Correa P. Classification and grading of gastritis. The updated Sydney System. International Workshop on the Histopathology of Gastritis, Houston 1994. Am J Surg Pathol 1996; 20: 1161-81.

17. Koletzko S, Jones NL, Goodman KJ, et al.; H. pylori Working Groups of ESPGHAN and NASPGHAN. Evidence-based guidelines from ESPGHAN and NASPGHAN for Helicobacter pylori infection in children. J Pediatr Gastroenterol Nutr 2011; 53: 230-43.

18. Henderson CJ, Ngeow J, Collins MH, et al. Increased prevalence of eosinophilic disorders in pediatric PTEN hamartoma tumor syndromes. J Pediatr Gastroenterol Nutr 2014; 58: 553-60.

19. Helgeland H, Flagstad G, Grøtta J, Vandvik PO, Kristensen $\mathrm{H}$, Markestad T. Diagnosing pediatric functional abdominal pain in children (4-15 years old) according to the Rome III Criteria: results from a Norwegian prospective study. J Pediatr Gastroenterol Nutr 2009; 49: 309-15.

20. Bauer S, Krumbiegel P, Richter M, et al. Influence of sociodemographic factors on Helicobacter pylori prevalence variability among schoolchildren in Leipzig, Germany. A long-term followup study. Cent Eur J Public Health 2011; 19: 42-5. 
21. Den Hoed CM, Vila AJ, Holster IL, et al. Helicobacter pylori and the birth cohort effect: evidence for stabilized colonization rates in childhood. Helicobacter 2011; 16: 405-9.

22. Oleastro $M$, Pelerito A, Nogueira P, et al. Prevalence and incidence of Helicobacter pylori Infection in a healthy pediatric population in the Lisbon area. Helicobacter 2011; 16: 363-72.

23. Ceylan A, Kirimi E, Tuncer O, Türkdoğan K, Ariyuca S, Ceylan N. Prevalence of Helicobacter pylori in children and their family members in a district in Turkey. J Health Popul Nutr 2007; 25: 422-7.

24. Altuglu I, Sayiner AA, Ozacar T, Egemen A, Bilgiç A. Seroprevalence of Helicobacter pylori in a pediatric population. Turk J Pediatr 2001; 43: 125-7.

25. Selimoglu MA, Ertekin V, Inandi T. Seroepidemiology of Helicobacter pylori infection in children living in eastern Turkey. Pediatr Int 2002; 44: 666-9.

26. Ozden A, Bozdayi G, Ozkan M, Köse KS. Changes in the seroepidemiological pattern of Helicobacter pylori infec tion over the last 10 years in Turkey. Turk J Gastroenterol 2004; 15: 156-8.

27. Hasosah M, Satti M, Shehzad A, et al. Prevalence and risk factors of Helicobacter pylori infection in Saudi children: a three-year prospective controlled study. Helicobacter 2015; 20: 56-63.

28. Wewer V, Andersen LP, Paerregaard A, et al. Treatment of Helicobacter pylori in children with recurrent abdominal pain. Helicobacter 2001; 6: 244-8.

29. Talley NJ. How should Helicobacter pylori positive dyspeptic patients be managed? Gut 1999; 45 (Suppl 1): 128-31.

30. Macarthur C. Helicobacter pylori infection and childhood recurrent abdominal pain: lack of evidence fo a cause and effect relationship. Can J Gastroenterol 1999; 13: 607-10.

31. O’Donohoe JM, Sullivan PB, Scott R, Rogers T, Brueton MJ, Barltrop D. Recurrent abdominal pain and Helicobacter pylori in a community-based sample of London children. Acta Paediatr 1996; 85: 961-4.

32. Ashorn M, Rägö T, Kokkonen J, Ruuska T, Rautelin $H$ Karikoski R. Symptomatic response to Helicobacter pylori eradication in children with recurrent abdominal pain: double blind randomized placebo-controlled trial. J Clin Gastroenterol 2004; 38: 646-50.

33. Bourke B, Ceponis P, Chiba N, et al. Canadian Helicobacter Study Group Consensus Conference: update on the approach to Helicobacter pylori infection in children and adolescents - an evidence based evaluation. Can J Gastroenterol 2005; 19: 399-408.

34. Al-Sinani S, Sharef SW, Al-Naamani K, Al-Sharji H. Helicobacter pylori infection in Omani children. Helicobacter 2014; 19: 306-11.

35. Ozen H, Dinler G, Akyon Y, Kocak N, Yuce A, Gurakan F. Helicobacter pylori infection and recurrent abdominal pain in Turkish children. Helicobacter 2001; 6: 234-8.

36. Thomson M, Tringali A, Dumonceau JM, et al. Paediatric Gastrointestinal Endoscopy: European Society for Paediatric Gastroenterology Hepatology and Nutrition and European Society of Gastrointestinal Endoscopy Guidelines. J Pediatr Gastroenterol Nutr 2017; 64: 133-53.

37. Samer Ammar M, Pfefferkorn MD, Croffie JM, Gupta SK, Corkins MR, Fitzgerald JF. Complications after outpatient upper Gl endoscopy in children: 30-day follow-up. Am J Gasterol 2003; 98: 1508-11.

38. Lee WS, Zainuddin H, Boey CC, Chai PF. Appropriateness, endoscopic findings and contributive yield of pediatric gastrointestinal endoscopy. World J Gastroenterol 2013; 19: $9077-83$ 